\title{
NOTE
}

\section{DIFFÉRENCE DE CROISSANCE LIÉE AU GÊNE « $R$ » CHEZ LES COQS}

\author{
P. MERAT \\ avec la collaboration technique de L. Der.ixn \\ Station de Recherches avicoles, \\ Centre national de Recherches sootechniques Jouy-en-Josas (Seinc-et-Oise)
}

Sur une population maintenue non fixée depuis In générations pour le gène $R$ de forme de la crête (cf. Múrat, I962), nous avons comparé, sur l'ensemble des années, le poids des animaux des deux types de crête, à 8 semaines d'âge, par la méthode des couples. Les deux membres de chaque couple choisi étaient pris au hasard parmi les frères ou sœurs nés le même jour, élevés ensemble, l'un étant hétérozygote pour la crête en rose $(\mathrm{R} r)$, l'autre à crête simple $(r r)$. Cps couples descendaient de croisements du type $\sigma^{x} \mathrm{R} r \times q r r$, ou $\sigma^{\top} r r \times \uparrow \mathrm{R} r$. La population était reproduite en troupeau fermé, à partir d'un croisement initial, sans consanguinité systématique. 'Tous les accouplements étaient pedigree, chaque mère n'étant accouplée qu'à un seul père, avec 7 à 8 mères pour chaque père. Les poulets étaient élevés au sol, avec ui aliment de type standard.

Ia comparaison des poids, par sexe, et suivant le type de croisement relativement au gène $R$, donne le résultat suivant :

TABI,EAU I

Comparaison des poids à 8 semaines

\begin{tabular}{|c|c|c|c|c|c|c|c|c|c|c|}
\hline & \multicolumn{5}{|c|}{$0^{*}$} & \multicolumn{5}{|c|}{ 우 } \\
\hline & \multirow{2}{*}{$\begin{array}{c}\text { Nombre } \\
\text { cle } \\
\text { comples }\end{array}$} & \multicolumn{2}{|c|}{$\begin{array}{l}\text { Poids moyen } \\
\text { (g) }\end{array}$} & \multirow[t]{2}{*}{$t$} & \multirow{2}{*}{$\begin{array}{l}\text { Proba- } \\
\text { bilité }\end{array}$} & \multirow{2}{*}{$\begin{array}{l}\text { Xombre } \\
\text { de } \\
\text { couples }\end{array}$} & \multicolumn{2}{|c|}{$\begin{array}{c}\text { Poids moyen } \\
(\mathrm{g})\end{array}$} & \multirow[t]{2}{*}{$t$} & \multirow{2}{*}{$\begin{array}{l}\text { Proba- } \\
\text { bilité }\end{array}$} \\
\hline & & $R r$ & $r r$ & & & & $k r$ & $r r$ & & \\
\hline $\mathrm{R} r \times r r$. & 688 & $7^{\prime} 16,5$ & 755,0 & $-1,523$ & 0,$0 ;-0,10$ & 671 & $033: 2$ & $(: 39,1$ & $-1,299$ & N.S. \\
\hline$r r \times k r .$. & 486 & 726,1 & 738,2 & - 2,087 & $<0,0 ; 5$ & 171 & $621, \mathrm{i}$ & 621,6 & $-0,050$ & N.S. \\
\hline Jotal & 1171 & 738,0 & $7+8,0$ & $-2,538$ & $<0,02$ & $11^{\prime}=2$ & 628,3 & $(331,9$ & $-1,126$ & N.S. \\
\hline
\end{tabular}


Au total, les mâles à crête en rose ont donc une croissance légèrement, mais très significativement, inférieure à celle des mâles à crête simple, ce qui, sur des données moins nombreuses (MÉRAT, Ig62 a) n'était pas apparu nettement.

Chez les femelles, une petits différence existe dans le même sens, mais elle n'est pas significative.

Dans aucun cas les variances ne diffèrent sensiblement pour les deux types de crête, comme l'indique le tableau 2 .

\section{TABIFAL 2}

Comparaison des rariances intra-annies (les deux types de croisement groupés)

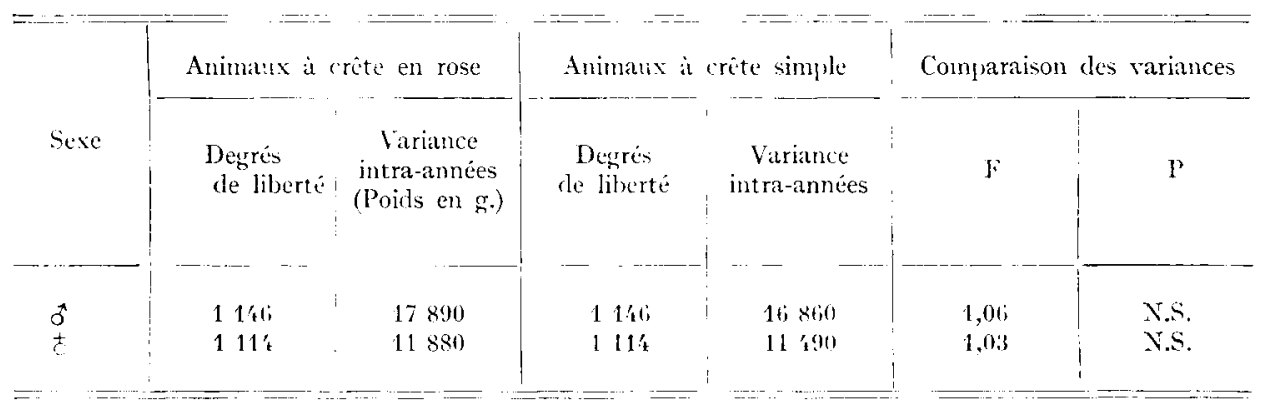

Nous n'avons pas, pour l'instant, d'éléments pour l'interprétation physiologique de cette différence de croissance, et sur le fait qu'elle est plus marquée chez les coquelets.

Il n'y a pas de différence significative dans la mortalité embryonnaire des zygotes $\mathrm{R} r$ et $r r$, du moins aux derniers stades de l'incubation (cf. Mérat, Ig62 b), ni dans la mortalité des jeunes, comme l'indique le tableau 3 portant sur l'ensemble des données (et non plus seulement sur les couples comparés pour le poids) :

\section{TABIEAU 3}

Morlatiti comparie de 0 à 8 scmaines pour les deux types de crête. (Toutes années groupées)

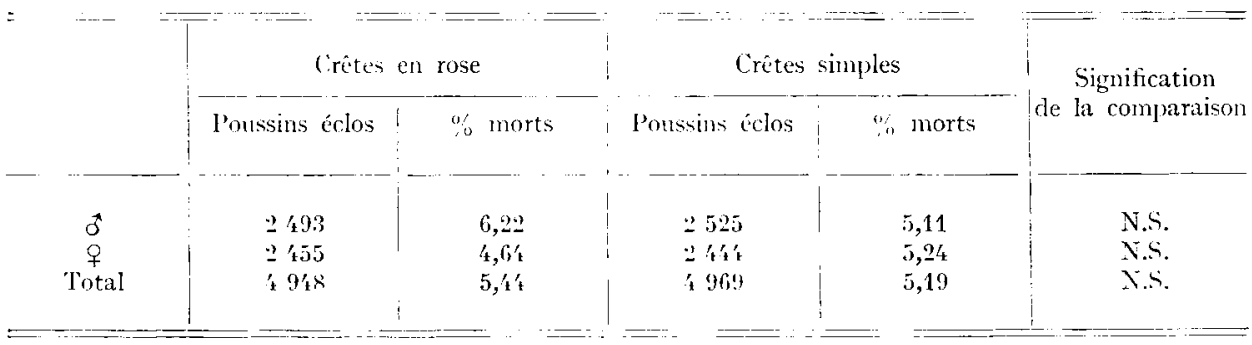

Il n'y a donc vraisemblablement pas d'élimination préférentielle des mâles qui auraient eu la plus mauvaise croissance, parmi ceux à crête simple.

Il ne paraît pas y avoir de différence dans le poids des mâles adultes (données 
non publiées). Par ailleurs, les coqs à crête en rose semblent avoir une activité sexuelle et une "agressivité " moindre que ceux à crête simple (PETITJEAN, communication personnelle; CRAWFORD, communication personnelle) ; des recherches seraient souhaitables pour savoir si une telle différence est déjà présente chez les jeunes et pourrait expliquer la différence de poids constatée.

Reçu pour publication cn mars 1965 .

\section{SUMMARY}

GROWTII DIFFERENCE FOR MALE CHICKS, ASSOCIATED WITH THE « $R$ » GENE

In a segregating strain, chicks heterozygous for rose comb $(\mathrm{R} r)$ were compared with recessive ones $(r r)$ for 8 - week weight. The comparison was restricted to pairs of full sibs of the same hatch. Single comb males were significantly heavier than rose comb ones. For females, the difference was not significant.

\section{RÉFÉRENCES BIBLIOGRAPHIQUES}

Yérat P., ig6z. Quelques relations entre caractères extérieurs à hérédité simple et productivité chez les volailles. C. R. $12^{\mathrm{e}}$ Congr. Mond. Avic., II, p. $7 \mathrm{I}-76$.

MḱRat P., rg62 b. Ségrégations anormales pour les allèles "crête simple " et "crête en rose " chez la poule. I. Croisement oै $\mathrm{R} r \times \frac{\text { q }}{r r}$. Ann. Biol. anim. Bioch. Biophys., 2, Iog-IT. 